\title{
Erratum to: Analyzing Patient Preference for Nipple-Areola Complex Reconstruction Using Utility Outcome Studies
}

\author{
Ahmed M.S. Ibrahim, Frank H. Lau, Hani H. Sinno, \\ Bernard T. Lee, and Samuel J. Lin
}

\section{Erratum to: \\ Chapter 79 in: M.A. Shiffman (ed.), Nipple-Areolar Complex Reconstruction, https://doi.org/10.1007/978-3-319-60925-6_79}

Erratum Text:

In the original version of chapter 79, the references 29 and 38 are repeated with different publication year.

29. Sinno H, Izadpanah A, Tahiri Y, et al. The Impact of Living With Severe Lower Extremity Lymphedema: A Utility Outcomes Score Assessment. Ann Plast Surg 2013.

38. Sinno H, Izadpanah A, Tahiri Y, et al. The Impact of Living With Severe Lower Extremity Lymphedema: A Utility Outcomes Score Assessment. Ann Plast Surg 2014;73:210-4.

The current version has been updated by deleting the duplication.

The updated original online version for this chapter can be found at https://doi.org/10.1007/978-3-319-60925-6_79

\begin{abstract}
A. M. S. Ibrahim, M.D., Ph.D. ( $₫)$ · F. H. Lau, M.D.
Division of Plastic and Reconstructive Surgery,

Louisiana State University Health Sciences Center,

1542 Tulane Avenue, New Orleans, LA 70112, USA

e-mail: aibra1@1suhsc.edu; flau@1suhsc.edu
\end{abstract}

H. H. Sinno, M.D.

Division of Plastic Surgery, McGill University,

Montreal, QC, Canada, H3A 0G4

e-mail: hanisinno@gmail.com

B. T. Lee, M.D., M.B.A., M.P.H. · S. J. Lin, M.D., M.B.A.

Division of Plastic and Reconstructive Surgery,

Beth Israel Deaconess Medical Center, Harvard Medical School,

110 Francis Street, Lowry Suite 5A, Boston, MA 02215, USA

e-mail: blee3@bidmc.harvard.edu; sjlin@bidmc.harvard.edu 